MISCELLANEA

\section{The Range of Vision Permitted by Protective Goggles}

\section{BY}

\author{
J. P. BULL \\ From the Medical Research Council Industrial Injuries and \\ Burns Research Unit, Birmingham Accident Hospital
}

(RECEIVED FOR PUBLICATION MAY 8, 1957)

In her review of ocular injuries and hazards at the British Occupational Hygiene Conference on Protective Equipment, Dr. Campbell called attention to some of the reasons why goggles are not used. ". . . many goggles have been devised-but so many steam up, restrict the field of vision and add so much to the discomfort of the workman that he will have none of them except in the processes for which he is legally obliged to wear them " (Campbell, 1956; Davies, 1956). The purpose of this note is to call attention to one of these factors-restriction of the field of vision-and to put forward a simple method of testing it.

When current types of goggles are examined it is found that there are two kinds of restriction of vision. The first and most obvious one is the limitation of peripheral vision due to opaque projections at the outer margins of the eyepieces. The less obvious but probably equally important limitation is that of binocular vision caused by opaque projections on the nasal edges of the eyepieces. Normally the limits of vision when eye movements are permitted are determined by the anatomical contours of the orbital region. The limiting structures are superiorly the eyebrows and laterally and inferiorly the tissues covering the orbital margin. Medially the tissues of the nose limit the vision of each eye and hence the degree of overlap of the visual fields available for binocular vision. In the laboratory, the exact extent of these fields can be plotted on a perimeter. Usually for ophthalmic purposes the peripheral vision is explored with the eye directed forwards, but when considering these measurements in relation to the occupational use of goggles, it is more appropriate to allow the eyes to move freely. The angular range so estimated is similar to that obtained with the eyes fixed, but measurements are easier since the test object can be seen more clearly. Precise measurements vary with different individuals, but normally an angle of rather more than $180^{\circ}$ can be swept if both eyes are used together. Of this range the overlap permitting binocular vision is about $100^{\circ}$ in the horizontal plane. If similar tests are made with the subject wearing standard goggles as supplied for industrial use, the restriction of vision becomes apparent. As an example, observations with a standard type of goggle intended primarily for welding processes show restriction of total lateral fields to $70^{\circ}$ and of the binocular field to $40^{\circ}$. The mechanism of this limitation is indicated in Fig. 1, from which it will be clear that any opaque structure encroaching upon the "beaten field" of the line of sight restricts vision. It may be objected that this is inevitable if the lens is to be adapted to the contours of the face. That this is not so can be seen from the diagram since projections in the region beyond the edge of the beaten field need not cause any restriction of vision. Since little, if any such area is available in the nasal region, it follows that projections in the region of the bridge of the nose will usually limit the binocular field. The simplest solution of this problem is to have a one-piece lens which extends beyond the beaten field. Ideally such a lens needs to be curved in two planes, like many modern car windscreens, so as to avoid any restriction of the peripheral field. A number of commercial goggles have been designed with these principles in mind, and it is a matter of technical development for suitable lenses to be produced in this shape for the varying hazards for which goggles are required.

Since measurements by perimetry are unlikely to be available in most factories, the following simple test is suggested by which the effect of any particular type of goggle on a workman's range of vision can be assessed. The test can be conveniently performed in the corner of a well-lit room. From the corner $(C)$ a distance of

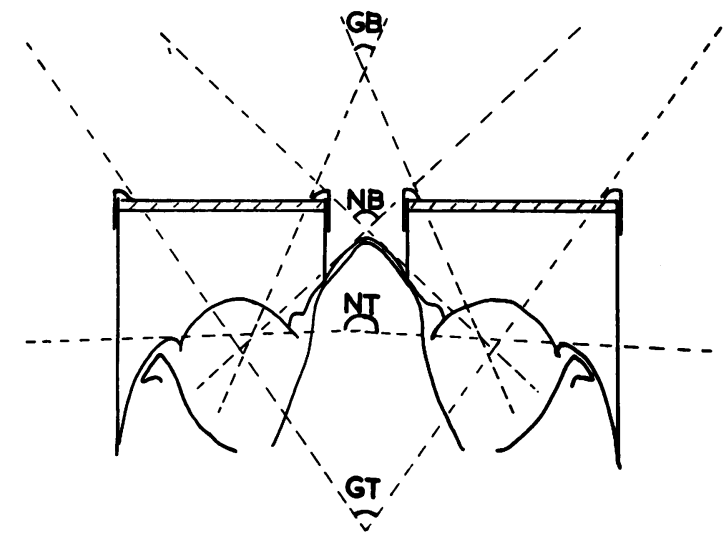

FIG. 1.-Diagrammatic horizontal section through the orbits, showing normal limits of lateral and binocular visual fields and the effect of goggles.

$$
\begin{array}{cccl}
\text { Angle } & \text { N } & \text { T. } & \text { Normal total range } \\
\text { " } & \text { N } & \text { B. } & \text { Normal binocular range } \\
\text { " } & \text { G } & \text { T. } & \text { Total range with goggles } \\
\text { " } & \text { G } & \text { B. } & \text { Binocular range with goggles }
\end{array}
$$



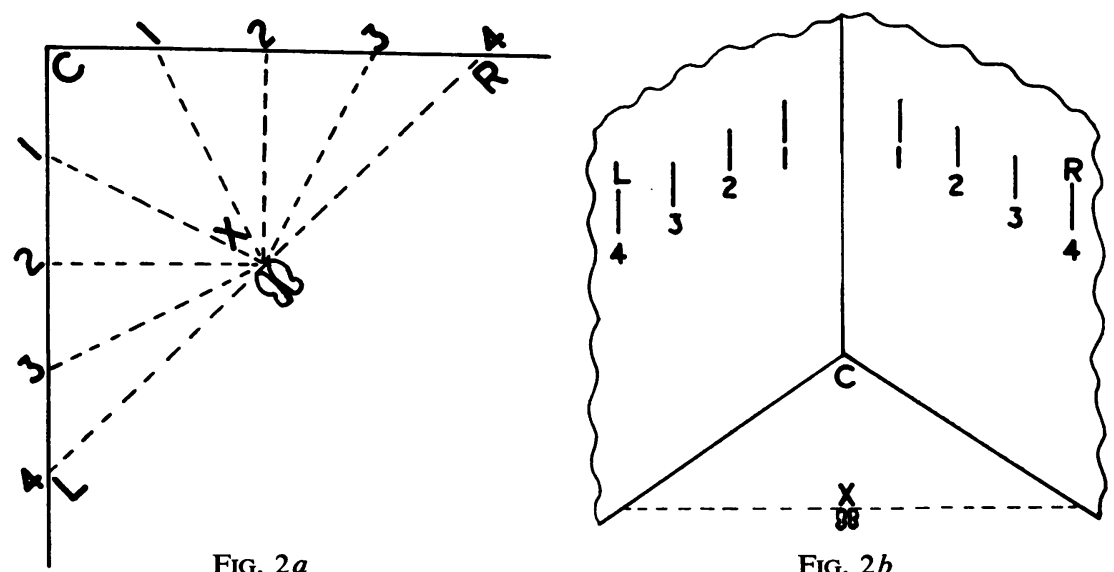

Fig. $2 a$

Fig. $2 b$

FIG. 2 ( $a$ and $b$ ).-Corner of room set out for test of range of vision permitted by goggles. (a) Plan. (b) General view.

$8 \mathrm{ft}$. is marked along each of the two walls at a height of about $5 \mathrm{ft}$. ( $R, L$, Fig. $2 \mathrm{a}$ and $\mathrm{b}) . C R$ and $C L$ are marked in quarters at $1,2,3$, and 4 . The marks may conveniently be vertical strips of adhesive paper. The position for standing $(X)$ is marked on the floor midway between $\boldsymbol{R}$ and $L$. The angles subtended to the subject are: $1-X-137^{\circ} ; 2-X-290^{\circ} ; 3-X-3143^{\circ} ; 4-X-4180^{\circ}$.

A normal person standing at $X$ and facing the corner, $C$, should see marks $R 4$ and $L 4$ when allowing the eyes to move. This corresponds to a total lateral range of $180^{\circ}+$. With the right eye occluded the mark $R 2$ will probably be seen with the left eye; correspondingly with the left eye occluded, mark $L 2$ will be seen with the right eye. This corresponds to a binocular range of $90^{\circ}+$. With many goggles it will be found that even $R 2$ and $L 2$ cannot be seen with lateral vision $\left(<90^{\circ}\right)$, and that the binocular overlap lies only between $R 1$ and $L 1\left(37^{\circ}\right)$. (Further intermediate marks may be made to allow more detailed comparisons; alternatively the marks may be rearranged to give direct readings in degrees, e.g., distances of $1 \mathrm{ft} .1 \mathrm{in}$. and $2 \mathrm{ft}$. $3 \frac{3}{4} \mathrm{in}$. laid off on both sides of $R 2$ and $L 2$ will give the series $30^{\circ}, 60^{\circ}, 90^{\circ}$, $120^{\circ}$, and $180^{\circ}$. A further refinement is to make a vertical series of marks at $R 2$ or $L 2$ to measure the permitted vertical range of vision.)

Many workmen who would benefit from eye protection by goggles work in shops where people and materials move about. Without goggles these men are aware of objects moving in the peripheral fields of vision, and normally hearing and sight combine to make sense of happenings in the vicinity. In this way the worker is warned of potential dangers, but if the range of vision is limited by goggles to half or less, the worker is at a disadvantage. His continuing awareness of the potential dangers in the environment is curtailed, and objects to the side can only be seen after turning the head. It may be objected that there would be no advantage for welders' goggles with their low transmission of light to admit a wider field, since other objects are not sufficiently illuminated to be seen. While this may be true for the particular case of protection against intense light, this pattern of goggle is frequently used for other purposes, and many will be found fitted with transparent lenses. It was because of this widespread use of the welder's goggle for general purposes that it has been taken as an example, but the same considerations can equally be applied to other patterns. In the last few years there has been a welcome development of designs which overcome many of these criticisms, but there is still room for their more general use and for other models to be developed which will meet the requirements of all occupations where the eyes are at risk.

\section{Summary}

Attention is drawn to the limitation of peripheral and binocular fields of vision by many industrial goggles.

A simple test of the permitted range of vision is described.

Greater use of wide-angle goggles is recommended where suitable patterns are available. Further development is needed of designs appropriate for all circumstances.

This work follows a suggestion by Professor J. R. Squire, Leith Professor of Experimental Pathology in the University of Birmingham, who was responsible for war-time operational research on a similar problem.

\section{REFERENCES}

Campbell, D. A. (1956). Brit. J. industr. Safety, 3, 184 Davies, C. N. (1956). British Journal of Industrial Medicine, 13, 76. 